\title{
Internet charity in Russia: conditions, forms and practices
}

\author{
N. V. Krainova ${ }^{1}$, A. A. Agurova ${ }^{1}$ \\ 1P. G. Demidov Yaroslavl State University, 14 Sovetskaya str., Yaroslavl 150003, Russian Federation \\ DOI: $10.18255 / 2412-6519-2021-1-18-27$ \\ Research Article \\ Full text in Russian
}

The article is devoted to the analysis of such a phenomenon in modern realities as Internet charity. The authors analyzed the forms of modern charity and its tools in the online reality, as well as considered specific campaigns using digital mechanisms. Charity is considered as a public detail, carried out exclusively on a voluntary basis. The main features are highlighted: the gratuitous basis; the choice of the place, volume and format of assistance; the social orientation of the activity, the subject of which can be either a private person or a legal entity; the non-state nature of the activity with possible state support for campaigns and NGOs. In modern Russian society, charity is not a national tradition. However, today there are a large number of charitable foundations, non-profit organizations, as well as private initiatives on the part of citizens. The virtualization process makes it possible to introduce modern tools and mechanisms into the usual spheres of life, thanks to which most of the processes are simplified and become accessible to a larger number of citizens. The sphere of charity is also no exception. The development of ICT makes it possible to spread information to a larger audience, to mobilize a larger number of stakeholders, and to optimize the donation process. The article deals with cases of charitable activity in the Internet environment, innovative forms of charity, as well as what functions are performed by modern tools of the studied activity. We can say that the Internet charity today acts as a significant and effective resource due to the availability, efficiency, visibility, and scale of the dissemination of socially oriented information.

Keywords: Charity; forms of charity; innovative forms of charity; Internet charity; subjects of Internet charity; voluntary activity; volunteerism

INFORMATION ABOUT THE AUTHORS

\begin{tabular}{|c|c|}
\hline $\begin{array}{r}\text { Krainova, Natalia } \mathrm{V} \text {. } \\
\text { (correspondence author) }\end{array}$ & $\begin{array}{l}\text { E-mail: nvkrainova@mail.ru } \\
\text { Cand. Sc. (Politics), associate Professor }\end{array}$ \\
\hline Agurova, Arina A. & $\begin{array}{l}\text { E-mail: tptch@yandex.ru } \\
\text { Student }\end{array}$ \\
\hline
\end{tabular}

For citation: Krainova N. V., Agurova A. A. Internet charity in Russia: conditions, forms and practices // Social'nye i gumanitarnye znanija. 2021. Vol. 7, No 1. P. 18-27. (in Russ.)

(C) Krainova N. V., Agurova A. A., 2021

This is an open access article under the CC BY license (https://creativecommons.org/licenses/by/4.0/) 


\title{
Интернет-благотворительность в России: условия, формы и практики
}

\author{
Н. В. Крайнова ${ }^{1}$, А. А. Агурова ${ }^{1}$
}

1Ярославский государственный университет им. П. Г. Демидова, ул. Советская, 14, Ярославль, 150003, Российская Федерация

Статья посвящена анализу такого явления в современных реалиях, как интернет-благотворительность. Авторами были проанализированы формы современной благотворительности и ее инструменты в онлайн-реальности, а также рассмотрены конкретные кампании с применением цифровых механизмов. Благотворительность рассматривается как общественная детальность, осуществляемая исключительно на добровольных началах. Выделяются основные черты: безвозмездная основа; выбор места, объема и формата помощи; социальная направленность деятельности, субъектом которой может быть как частное лицо, так и юридическое; негосударственный характер деятельности при возможной поддержке государством кампаний и НКО. В современном российском обществе благотворительность не является национальной традицией. Однако на сегодняшний день существует и действует большое количество благотворительных фондов, некоммерческих организаций, а также частных инициатив со стороны граждан. Процесс виртуализации позволяет внедрять в привычные сферы жизни современные инструменты и механизмы, благодаря которым большая часть процессов упрощается и становится доступной большему числу граждан. Сфера благотворительности также не является исключением. Развитие ИКТ позволяет распространять информацию на большую аудиторию, мобилизовать большее количество заинтересованных лиц, а также оптимизировать процесс пожертвований. В статье рассмотрены кейсы благотворительной деятельности в интернет-среде, инновационные формы благотворительности, а также функции, выполняемые современными инструментами изучаемой деятельности. Можно сказать, что интернет-благотворительность на сегодняшний день выступает в качестве значимого и действенного ресурса благодаря доступности, оперативности, наглядности, масштабности распространения социально направленной информации.

Ключевые слова: благотворительность; формы благотворительности; инновационные формы благотворительности; интернет-благотворительность; субъекты интернетблаготворительности; добровольческая деятельность; волонтерство

\section{ИНФОРМАЦИЯ ОБ АВТОРАХ}

Крайнова, Наталия Вячеславовна (автор для корреспонденции)

Агурова, Арина Алексеевна
E-mail: nvkrainova@mail.ru

Кандидат политических наук, доцент кафедры социальнополитических теорий

E-mail: tptch@yandex.ru Студент

Для цитирования: Крайнова Н. В., Агурова А. А. Интернет-благотворительность в России: условия, формы и практики // Социальные и гуманитарные знания. 2021. Том 7, № 1. С. 18-27. 


\section{Введение}

Понятие благотворительности трактуется множеством авторов. В. Г. Белинский был одним из первых, кто дал научное объяснение термина. Он трактовал благотворительность как оказание помощи, где фундаментом служит любовь к ближнему. В толковом словаре русского языка С. И. Ожегова дается следующее понимание термина: благотворительность - действия и поступки безвозмездного характера, направленные на общественную пользу или на оказание материальной помощи неимущим [1]. Т. Г. Деревягина трактует благотворительность через призму социальной системы учреждений и институтов, главная цель которых - решение проблем наименее защищенных граждан [2, с. 39].

В основном авторы не упоминают в своих трактовках субъекта благотворительной деятельности. Однако Э. А. Фомин и Е. З. Чикадзе трактуют понятие именно с точки зрения субъектной направленности исследуемой деятельности и говорят о ее роли. Таким образом, они трактуют благотворительность как негосударственную добровольную безвозмездную деятельность в социальной сфере, направленную на поддержку отдельных лиц или организаций, у которых по тем или иным причинам не хватает ресурсов для полноценного функционирования. При этом поддержка, оказываемая на основе родственных, соседских, дружеских и иных личных связей, не рассматривается как социальный феномен благотворительности [3].

Принимая во внимание трактовки различных авторов, можно сказать, что благотворительность - это общественная детальность, осуществляемая исключительно на добровольных началах.

В качестве отличительных черт данной деятельности можно выделить следующие: безвозмездная основа; выбор места, объема и формата помощи также является добровольным; деятельность носит социальную направленность, субъектом может быть как частное лицо, так и юридическое; как правило, это негосударственная деятельность, но государство может оказывать поддержку в деятельности кампаний, НКО и иных источников.

Благотворительность - это не только финансовая помощь. Это также может быть проведение консультаций, тренингов, образовательные программы и иная нематериальная помощь. Таким образом, основной целью благотворительной деятельности является оказание помощи и поддержки нуждающимся гражданам, организациям или культурным объектам, но никак не получение прибыли или ангажирование политическими интересами.

\section{Современные формы благотворительности}

В своей работе «Традиционные и инновационные формы благотворительности в России» Н. Н. Пешкова представляет классификацию благотворительной деятельности. С одной стороны, автор выделяет традиционные формы, которые сложились в ходе многовековой истории нашей страны. К ним Н. Н. Пешкова относит милосердие, подаяние, пожертвование, спонсорство, волонтёрство, дарственный обмен и филантропию. В свою очередь, в инновационные формы входят эндаумент, фандрайзинг, спонсоринг, венчурная благотворительность и социальное служение [4, c. 45]. Последним формам хотелось бы уделить большее внимание, поскольку они являются достаточно современными и менее изученными на сегодняшний день. 
Эндаумент - это целевой фонд, который, как правило, осуществляет свою деятельность в некоммерческих целях, в основном ориентированных на образовательную, медицинскую или культурную сферу [5]. Большей частью подобные фонды ориентированы на длительную деятельность и в среднем функционируют от 10 лет. Основным источником формирования средств подобных организаций являются добровольные имущественные взносы и благотворительные пожертвования от граждан, предприятий, организаций и учреждений. Конечно, фонд имеет право инвестировать в различные проекты, программы или кампании с целью извлечения коммерческой прибыли или выгоды, но доход необходимо направлять в пользу тех объектов и организаций, на поддержку которых изначально был нацелен эндаумент.

Краудфандинг можно определить как поиск и привлечение материальных и иных ресурсов, при котором массовый характер взносов позволяет даже при небольшом размере личного вклада каждого участника добиваться значительной эффективности. Сбор средств с помощью краудфандинговых технологий может использоваться для решения разнообразных задач, но сегодня он в большей степени используется в благотворительности [6].

Схема краудфандинга достаточно простая: один человек может выдвинуть идею, подробно описав шаги по ее осуществлению, указать сумму, которую необходимо собрать, а единомышленники или просто заинтересованные люди поддерживают с помощью финансовых вложений. Зачастую автор мотивирует граждан осуществлять взносы с помощью бонусов. Например, если это какой-то материальный продукт, который будет производиться в больших количествах, то участники с самым большими пожертвованиям получат эксклюзивный материал первыми и т. д.

На сегодняшний день в России основными площадками являются «Boomstarter», «Планета», «С миру по нитке», «Thankyou», «Русини», «Кroogi» и т. д. У каждой из платформ может быть своя направленность и свои правила сбора денежных средств. Например, площадка «Thankyou» в основном специализируется на музыкальных и творческих работах, а вот «Русини» занимается поддержкой именно социально-направленных проектов (защита окружающей среды, программы для детей, развитие социального бизнеса и т. д.).

Спонсоринг, как отмечает в своей работе Н. Н. Пешкова, достаточно новое явление для России, которое, таким образом, является привлекательным для исследователей [4, с. 46]. Отчасти новизна связана с тем, что сам спонсоринг связан с маркетингом и PR. Иными словами, это комплекс мероприятий, который направлен на поддержку в организации проекта. Как правила, главной целью спонсоринга является продвижение, формирование имиджа, а также помощь в техническом проведении кампании (фестиваля, программы и т. д.).

Венчурная благотворительность или венчурная филантропия - благотворительная деятельность, где основным источником дохода являются венчурные предприятия и бизнес в сфере социальной ответственности.

\section{Законодательная сторона вопроса}

В Российской Федерации на сегодняшний день действует закон «0 благотворительной деятельности и благотворительных организациях» № 135 Ф3 от 11.08.1995 г. В данном нормативном акте благотворительность трактуется как 
добровольная деятельность граждан и юридических лиц по бескорыстной (безвозмездной или на льготных условиях) передаче гражданам или юридическим лицам имущества, в том числе денежных средств, бескорыстному выполнению работ, предоставлению услуг, оказанию иной поддержки ${ }^{1}$. Упомянутый закон также предусматривает основные цели благотворительной деятельности, а именно:

- социальная поддержка и защита граждан, в том числе поддержка малообеспеченных граждан, социальная помощь нетрудоспособным лицам;

- помощь гражданам и их реабилитация после стихийных бедствий, экологических и иных катастроф непреодолимой силы;

- предотвращение социальных конфликтов, конфликтов на национальной или религиозной почве;

- содействие в поддержке укрепления института семьи, поддержка материнства и отцовства;

- содействие деятельности в сфере образования, науки, культуры, искусства, просвещения, духовного развития личности и многое другое.

Как правило, все указанные цели имеют социальный и гуманитарный характер и направлены на гармонизацию отношений между различными субъектами разных групп с ориентацией на поддержание мира и развитие положительных для общества качеств (содействие в образовательной, духовной, творческой сфере). Помимо конкретных целей, которые должны ставиться в основу любой благотворительной деятельности, закон предусматривает и ограничения. Например, согласно статье 12 из Ф3 «0 благотворительной деятельности и благотворительных организациях», благотворительная организация не вправе расходовать свои средства и использовать свое имущество для поддержки политических партий, движений, групп и кампаний.

Источниками для благотворительной деятельности могут служить, во-первых, членские взносы, взносы от учредителей благотворительной организации; вовторых, это могут быть поступления от проведенных кампаний по привлечению благотворителей и волонтеров; в-третьих, благотворительные пожертвования (это могут быть пожертвования от медийных лиц, гранты, целевые программы и т. д.).

Выделяют несколько субъектов благотворительной деятельности. Федеральный закон № 135 трактует, что участниками таковой деятельности являются граждане и юридические лица, осуществляющие благотворительную деятельность, в том числе путем поддержки существующей или создания новой благотворительной организации, а также граждане и юридические лица, в интересах которых осуществляется благотворительная деятельность: благотворители, добровольцы (волонтеры), благополучатели. Участниками волонтерской деятельности являются добровольцы, организаторы добровольческой деятельности и волонтерские организации.

В иных трактовках можно встретить выделение следующих субъектов: коммерческие структуры, которые являются материальным базисом для осуществления благотворительной деятельности; НКО - организации, которые действуют

\footnotetext{
${ }^{1}$ Федеральный закон РФ от 11.08.1995 г. № 135-Ф3 «О благотворительной деятельности и благотворительных организациях》 [в последней редакции] КонсультантПлюс. // URL: http://www.consultant.ru/document/cons_doc_LAW_7495/(дата обращения: 05.11.2020).
} 
для поддержки граждан в социальном секторе, также оказывают материальную помощь и перечень бесплатных услуг различным категориям граждан; физические или юридические лица, действующие в рамках своих возможностей и инициативности, которые участвуют в благотворительной деятельности самовольно и независимо через личные пожертвования или труд в некоммерческих организациях. В качестве отдельного и развивающегося субъекта можно выделить грантодателей. Это физическое или юридическое лицо, которое имеет право на предоставление грантов согласно действующему законодательству. На сегодняшний день мы можем выделить несколько видов грантодателей: международного уровня (Фонд развития ООН, Детский фонд ООН (ЮНИСЕФ) и др.), государственные программы (Фонд президентских грантов, Российский научный фонд, Фонд содействия развитию малых форм предприятий в научно-технической сфере и т. д.), а также частные семейные корпоративные фонды (Благотворительный фонд Владимира Потанина, фонд Елены и Геннадия Тимченко, Благотворительный Фонд Константина Хабенского).

Объектами же благотворительности традиционно являются граждане, которые нуждаются в социальной защите, имеют трудности со здоровьем, материальным положением, последствиями катастроф, а также можно обозначить целые сферы: здравоохранение, культура, образование и т. д.

\section{Интернет-благотворительность: инструменты, механизмы, функции, субъекты}

На сегодняшний день в эпоху цифровизации и глобализации нельзя не отметить влияние роли сети Интернет на многие сферы, в том числе на благотворительность. Современные технологи значительно упрощают процессы коммуникации, деятельности, пожертвований. Выше мы упоминали инновационные формы благотворительной деятельности, и как раз в их контексте главным инструментом являются информационные технологии. Благодаря ИКТ становится все заметнее и значительнее коллективное сотрудничество людей, которые добровольно объединяют свои денежные средства или иные ресурсы, чтобы поддержать усилия других людей или организаций [7, с. 27].

Невозможно не отметить рост и уровень влияния социальных сетей на развитие благотворительности в настоящее время. На просторах таких социальных сетей, как Facebook, ВКонтаке, Twitter, Одноклассники, Instagram и других, можно встретить организованные группы помощи, тематические сообщества, которые в современных реалиях эпохи цифровизации являются важнейшими инструментами для распространения и продвижения информации о благотворительной деятельности и социальных проектах [Там же]. Пользователи используют и личные страницы, статусы, «истории», где можно легко распространить необходимую информацию о нюансах благотворительности. По данным исследования благотворительного фонда развития филантропии, большая доля российских НКО (примерно 67 \%) предпочитает использовать социальные сети для своей деятельности. Самой же популярной, по результатам исследования, оказалась социальная сеть «ВКонтакте», почти все опрошенные НКО отметили, что пользуются ВКонтакте (93 \%) 
и считают своё присутствие во ВКонтакте важным (77 \%). На втором месте по популярности - Facebook (87 \% пользователей отметили своё присутствие в данной социальной сети) [8].

По мнению опрошенных, социальные сети позволяют выполнять следующие функции:

- информирование граждан об основной повестке фонда, организации или программы;

- мобилизация сторонников благотворительной деятельности;

- привлечение волонтёров;

- сбор пожертвований с помощью онлайн-инструментов и виджетов в социальных сетях.

Одним из главных направлений любой некоммерческой организации является привлечение внимания к социально значимой проблеме. Таким образом, для такого сектора особенно важно увеличивать свою целевую аудиторию, привлекать партнеров, которые были бы вовлечены в благотворительную деятельность. В таком контексте интернет-технологии являются эффективным инструментом для решения подобной задачи.

Например, сегодня перевод в нужный фонд или частному лицу можно сделать по QR-коду, наведя на который можно в короткий срок перевести необходимую сумму, а реквизиты будут заполнены автоматически. Благотворительные организации достаточно быстро реагируют на информационную трансформацию и технические новинки, ведь самое важное - использовать все возможные механизмы для привлечения граждан к помощи. Такие коды легко создаются, могут содержать большое количество информации, а также исключают неудобства при отсутствии наличных денежных средств у желающих сделать пожертвовании. В большинстве своем QR-коды используют для распространения информации о фонде/кампании/проекте. Благотворительные фонды формируют коды со ссылкой на свой сайт на плакатах, рекламных страницах в бумажной прессе, флаерах, майках и буклетах. Например, организация помощи бездомным в Великобритании проводила акцию: в различных посещаемых местах города располагались «спальные места обездоленных», где на куске картона был изображен QR-код, перенаправляющий на сайт организации [9]. В России также есть пример, заслуживающий внимания. Благотворительный фонд «Совершай Добро», главная цель которого - оказание помощи детям с тяжелыми заболеваниями, запустил проект «Добрый QR-код». На разные суммы фонд сформировал отдельные QR-коды, при наведении камеры на которые пользователь тут же перенаправлялся на страницу с заполненными реквизитами, где оставалось только подтвердить платеж. На официальных сайтах фондов, как правило, надежность подобных переводов обеспечена с помощью шифрования данных и современной технологии 3D-Secure.

\section{Кейсы интернет-благотворительности}

Примечательным в российском сегменте является кейс благотворительного фонда «Подари жизнь» Дины Корзун и Чулпан Хаматовой и благотворительного фонда Константина Хабенского. Это одни из наиболее крупных фондов, которые ведут свою деятельность также на платформах социальных сетей. Например, в социальной сети «ВКонтакте» у сообществ данных фондов на данный момент более 
77 тысяч и 43 тысяч подписчиков соответственно. В своих тематических сообществах фонды публикуют всю необходимую информацию о своей деятельности, сообщают последние новости, представляют отчеты о проделанной работе, а также публикуют призывы о персонализированной помощи. Более того, помимо информативной функции, социальные сети имеют полезные виджеты, которые располагаются в самом начале сообщества и позволяют перевести любую сумму в фонд, не покидая онлайн-страницу. В сообществе «Подари жизнь» также указаны дополнительные ссылки на иные социальные сети, официальный сайт, а также прикреплены полезные статьи и пр. Такие инструменты позволяют с легкостью получить информацию в удобном для пользователя формате из различных источников. Подписавшись на сообщество, пользователь, помимо того, что публикации фонда будет видеть в своей ленте новостей, может также подключить индивидуальные уведомления, чтобы не пропустить ни одной новостной повестки из выбранного сегмента.

Помимо фондов федерального уровня, в социальных сетях могут получить широкую огласку и региональные организации. Например, благотворительный фонд в Вологодской области «Хорошие люди» обладает такими же возможностями за счет открытости площадки и аккумулирует вокруг себя большую для региона целевую аудиторию - более 9 тысяч подписчиков. Отличие лишь в том, что объект благотворительной деятельности - исключительно жители области.

Интересным кейсом может служить также присутствие банковского сектора как института благотворительной деятельности. Примером может являться программа лояльности одного из системно значимых банков в России. Согласно условиям программы, в качестве обмена полученного вознаграждения можно было напрямую выбрать пожертвование в благотворительный фонд помощи инвалидам и пожилым людям «Старость в радость». Таким образом, за совершение покупок и соблюдение правил можно напрямую из мобильного приложение совершить пожертвование в фонд. Такие простота и удобство могут замотивировать граждан принять участие в благотворительной деятельности того или иного фонда. В эпоху цифровизации для пользователя является значительно важным выполнять операции наиболее оперативно, не покидая своё мобильное устройство, а также избегая длительных переходов, звонков, заполнение анкет и т. д.

Субъектом подобной добровольческой деятельности могут быть не только крупные фонды, программы, организации и т. д., но и отдельный актор. Социальные сети позволяют самостоятельно генерировать повестку, проецировать свои намерения, цели и личные инициативы. С помощью постинга, личного сообщества, крупной аудитории (подписчиков) или таргетированной рекламы (при необходимости) можно поддержать уже действующие организации или фонды. Ярким примером может служить фотограф из Москвы Артём Арутюнов и его сообщество ArtofConsequences. На апрель 2020 года у фотографа более 76 тысяч подписчиков и средний индекс вовлеченности относительно просмотров - 3,3 \%, что является достаточно высоким показателем для социальной сети. В связи с эпидемиологической ситуацией в стране в начале 2020 года фотограф объявил о личной акции в поддержку врачей в России. Артём предлагает личные наработки в работе с фотографией, но основным условием было пожертвование на любую сумму в один из фондов поддержки врачей - Благотворительный фонд «Правмир» или «Созидание». Пост получил огромный отклик и собрал более 263 тысячи просмотров, более 700 лайков и 100 репостов. Помимо данного кейса, в социальной сети «ВКонтакте» 
проходит массовый интернет-флэшмоб \#историяблагодарности. Данный флэшмоб был организован с помощью еще одного мощного онлайн-инструмента - хэштэга. С его помощью предоставляется возможность найти слова поддержки врачам, возможность помочь иным фондам, а также принять самостоятельное участие в подобной благотворительной деятельности.

Благотворительный фонд развития филантропии «КАФ» провело исследование «Как развиваются и сколько зарабатывают денег онлайн-платформы в России». Первые платформы для онлайн-пожертвовании в России появились порядка десяти лет назад. Иными словами, подобные платформы - это своего рода сервис, который позволяет как НКО, так и юридическому и частному лицу быстро и безопасно осуществить пожертвование в пользу того или иного благотворительного проекта или программы. На сегодняшний день насчитывается уже более десяти работающих платформ: «Благо.pу», «Boomstarter», «Добро.Mail.ru», «Нужна помощь», «ВСЕМ» и т. д.

Появление подобных платформ увеличило количество пожертвований. По данным фонда «КАФ», с 2013 года на платформах было собрано более 1 миллиарда рублей в поддержку НКО. В 2018 году объём пожертвований через платформы составил около 407 миллионов рублей, что на 58 миллионов больше, чем в 2017 году. Наибольший объём пожертвований собирает информационный портал «Такие дела» - формат популярного СМИ о благотворительности оказался эффективным способом привлекать средства массовой аудитории. В четвёрку лидеров входят также «Добро.Mail.ru», Planeta.ru, «Благо.ру» [10].

\section{Выводы}

Исходя из всего вышесказанного, хотелось бы отметить, что доступность и возрастающее влияние интернет-технологий порождают новые формы и способы коммуникации во многих сферах современности, в том числе и благотворительности. Зачастую сетевое воздействие и онлайн-реальность формируют все новые ценности, возможности, ориентации, мироощущение и мировоззрение пользователя. На сегодняшний день ИКТ напрямую модернизируют благотворительную деятельность [11, с. 145]. Сетевое взаимодействие способствует привлечению все большего числа единомышленников, партнеров, спонсоров, повышается уровень информированности о существующих социальных проблемах, требующих коллективного взаимодействия и усилий. Оптимизация процесса пожертвований также повышает доступность помощи большему количеству нуждающихся для большего круга лиц. Таким образом, можно с уверенностью сказать, что процесс виртуализации активно развивает сферу благотворительной деятельности.

\section{Ссылки / References}

1. Ожегов С. И., Шведова Н. Ю. Толковый словарь русского языка. М.: ИТИ Технологии, 2003. $941 \mathrm{c}$.

2. Деревягина Т. Г. Теоретико-методологические аспекты благотворительности // Социальные технологии, исследования. 2006. № 4. С. 35-46.

3. Фомин Э. А., Чикадзе Е. З. Благотворительность как социокультурный феномен в России. СПб.: Питер, 1999. 112 с. 
4. Пешкова Н. Н. Традиционные и инновационные формы благотворительности в России // Омский научный вестник. 2011. № 101. С. 43-46.

5. Сидоров Д. Эндаумент: что это такое и как может помочь российским школам? // Такие дела. 15.04.2019. URL: https://takiedela.ru/news/2019/04/15/endowment-faq/ (дата обращения: 05.03.2020).

6. Кубасов К. А. Развитие инновационных методов инвестирования частного капитала и возможности их применения // Актуальные проблемы гуманитарных и естественных наук. 2012. № 12. С. 182-186.

7. Карагодина О. А. Интернет-благотворительность как социальный феномен современного российского общества // Новый университет. Серия: Актуальные проблемы гуманитарных и общественных наук. 2012. № 9 (18). С. 26-29.

8. Роль социальной сети ВКонтакте в развитии и продвижении НКО // КАФ Благотворительный фонд развития филантропии: сайт. URL:

http://www.cafrussia.ru/page/rol_socialnoi_seti_vkontakte_v_razvitii_i_prodvizhenii_nko (дата обращения: 05.03.2020).

9. QR-благотворительность: сканируй и жертвуй // Content-Review.com. 21.12.2012. URL: https://www.content-review.com/articles/19991/amp/ (дата обращения: 05.03.2020).

10. Филантроп Электронный журнал благотворительности // КАФ Благотворительный фонд развития филантропии: сайт. URL:

https://special.philanthropy.ru/platforms\#rec57006205 (дата обращения: 05.03.2020).

11. Борисова Ю. С. Сетевые ресурсы интернет-пространства как фактор модернизации благотворительной деятельности // Международный студенческий научный вестник. 2015. № 5-1. С. 143-145. 